\title{
Corpos deslocados: Relações entre política, estética e ativismo ambiental
}

Marcela de Andrade Gomes. Universidade Federal de Santa Catarina. Kátia Maheirie. Universidade Federal de Santa Catarina.

Marco Aurélio Máximo Prado. Universidade Federal de Minas Gerais. Lupicínio Iñiguez Rueda. Universitat Autònoma de Barcelona.

\section{Resumo}

A heterogeneidade das formas de ativismo e resistência tem inscrito na esfera pública uma multiplicidade de cenas políticas que nos direciona a problematizar a polifonia e polimorfose dos sujeitos políticos contemporâneos. Nesta seara, este artigo tem como objetivo problematizar o próprio conceito de política, a partir da análise de algumas ações da Organização nãoGovernamental (ONG) Greenpeace, com intuito de propiciar reflexões em torno da emergência do sujeito político no contexto atual. A partir da tese de Jacques Rancière de que a base da política é estética, este texto discute algumas intervenções realizadas pelo Greenpeace, atrelando o debate político à esfera da reconfiguração sensível na vida coletiva. A partir de nossas análises, temos compreendido que o Greenpeace tem criado novas formas de inserção e transformação do espaço público em político, reinventando formas de militância mais fluidas, criativas e irreverentes que, em alguma medida, desestabilizam a gramática discursiva hegemônica da ordem vigente.

Palavras-chave: política; estética; movimentos sociais.

\begin{abstract}
Bodies displaced: Politics, aesthetics and environmental activism. The heterogeneity of forms of activism and resistance have inscribed in the public sphere a multiplicity of political scenes that make us to problematize the polyphony and polymorphism of contemporary political subjects. This paper aims to problematize the concept of politics, inspired by the analysis of Nongovernmental Organization (NGO) Greenpeace's actions, producing some reflections about the emergence of the political subject in the current context. From Jacques Rancière's thesis that the basis of politics is an aesthetic, we discuss Greenpeace's actions, linking the political debate to the sphere of sensible in a contemporary collective life. From our analysis, Greenpeace has created new forms of insertion and transformation of public space into political, reinventing more fluid, creative and irreverent forms of militancy that can destabilize the hegemonic discursive grammar of the hegemonic order.
\end{abstract}

Keywords: politics; aesthetics; social movements.

\section{Resumen}

Cuerpos fuero de lugar: Las relaciones entre politica, estetica y activismo ambiental. La heterogeneidad del activismo y la resistencia ha generado en la esfera pública una multiplicidad de escenarios políticos que nos llevan a cuestionar la polifonía y polimorfosis de los sujetos políticos contemporáneos. En este sentido, este artículo trata de problematizar el concepto mismo de política, a partir del análisis de algunas de las acciones de la organización no gubernamental (ONG) Greenpeace, con el objetivo de proporcionar reflexiones sobre la emergencia del sujeto político en el contexto actual. A partir de la afirmación de Jacques Rancière de que la base de la política es estética, este texto analiza algunas intervenciones realizadas por el Greenpeace, llevando el debate político a la esfera de la reconfiguración de lo sensible en la vida colectiva. De nuestro análisis, se deriva que Greenpeace ha creado nuevas formas de intervención y transformación del espacio público en las formas políticas, creando una militancia más fluida, creativa e irreverente que, en cierta medida, desestabiliza el orden gramatical del discurso hegemónico. Palabras clave: política; estética; movimientos sociales. 
A heterogeneidade das formas de ativismo e resistência tem inscrito na esfera pública uma multiplicidade de atos e cenas políticas que nos direciona a problematizar a polifonia e polimorfose dos sujeitos políticos contemporâneos. O atual hibridismo político tem incitado inúmeros debates acadêmicos em torno das possibilidades, alternativas e estratégias de intensificação, ou não, dos processos democráticos e das reinvenções da política (Blisset \& Brunzels, 2006; Fernández, 1999; Oliveira, 2006; Sakamoto, 2013; Vinade \& Guareschi, 2007).

Nesta seara, este artigo tem como objetivo problematizar o próprio conceito de política, a partir da análise de algumas ações da Organização não Governamental (ONG) Greenpeace, com intuito de propiciar reflexões em torno da emergência do sujeito político no contexto atual. A partir da tese de Rancière (2005a, 2009, 2011a, 2012) de que a base da política é estética, este texto discute algumas intervenções realizadas pelo Greenpeace, atrelando o debate político à esfera da configuração sensível, da desconstrução de sentidos, apostando na criatividade e irreverência de suas ações públicas.

O Greenpeace, criado na década de 1970 no Canadá, é uma ONG internacional, presente em mais de 40 países, atuante na luta ambiental que defende um modo de vida mais sustentável, trabalhando na construção de alternativas economicamente viáveis e socialmente justas (Greeanpeace, 2010). O Greenpeace conta com aproximadamente: 4 milhões de colaboradores (pessoas físicas que doam dinheiro de forma sistemática à organização); 18 mil voluntários (pessoas que voluntariamente realizam as ações na esfera pública); 2000 funcionários que atuam nos escritórios distribuídos em 43 países (Gabeira, 1988; Greenpeace, 2010).

Nesse artigo apresentaremos, primeiramente, alguns apontamentos conceituais das reflexões de Jacques Rancière que sustentarão a discussão deste trabalho a partir do pressuposto de que a base da política é a estética. Em seguida, descreveremos o método e procedimentos de pesquisa utilizados e, por fim, apresentamos um rol de discussões realizadas sobre algumas intervenções do Greenpeace, em especial, aquelas que enriquecem o debate entre estética e política. A pesquisa desenvolvida teve como objetivo compreender as ações do Greenpeace a partir de dois conceitos centrais: os sujeitos políticos da ação, consequentemente, a noção de agência que aí se revela e a relação entre política e estética que incide na concepção de sujeitos políticos. Para tal, buscamos através da análise de documentos, da observação de algumas intervenções do Greenpeace e de entrevistas com ativistas, explorar as possibilidades e paradoxos da política na contemporaneidade.

\section{Estética e Política: possibilidades na reconfiguração do sensível na partilha coletiva}

O conceito de estética tem origem na palavra aisthesis que remete à dimensão do sensível e da sensibilidade humana. Desde a época da Grécia Antiga, a estética esteve ligada à produção artística, ocupando, no pensamento europeu moderno, o centro do debate entre arte e ciência, ou entre sensibilidade e racionalidade. Pautados nesta ótica, partimos da compreensão de que a estética não se restringe ao meio artístico, mas, se refere às maneiras de configurar a experiência sensível coletiva. A estética, conforme Rancière (2005a), está relacionada ao ritmo, aos sentidos, a um sensorium da vida coletiva que institui determinadas configurações da experiência comum que nos sãos possíveis ou não na vida em sociedade. Assim, a estética é a "forma pela qual os corpos se encontram em comunidade" (Rancière, 1996, p. 19), de como uma cena "torna-se manifesta, torna-se um aisthesis" (p. 55), definindo-a como "un modo de configuración sensible, un reparto de lugares y cuerpos cuya ruptura o emergencia determina la cosa misma de la política" (Vila, 2011, p. 20).

Sob a leitura de Rancière (2005a), a estética é política, pois o ritmo coletivo sensorializa determinadas experiências e invibiliza outras, marcando, dessa forma, a partilha como inexorável à vida em sociedade. Sendo assim, a política não é entendida como uso e luta do poder, mas, sim, como um campo litigioso em que uma diversidade de visões de mundo disputam lugares de reconhecimento e legitimidade na divisão do sensível. Tal partilha é definida como sendo: "o sistema de evidências sensíveis que revela, ao mesmo tempo, a existência de um comum e dos recortes que nele definem lugares e partes respectivas (...) fixa, portanto, ao mesmo tempo, um comum partilhado e partes exclusivas" (Rancière, 2005a, p. 15).

Um determinado sistema de evidências configura, esteticamente, determinadas experiências, revelando e inscrevendo como cada um toma parte nesta partilha, processo este atravessado por tensionamentos constantes os quais buscam ser "contados" nesta 
divisão da vida coletiva. Sob esta ótica, a política não está pautada no diálogo, nos acordos e consensos; ao inverso, ela irrompe quando fissura, desestabiliza e interpela este "sistema equilibrado"- ou, como nas palavras do autor, quando ela "quebra a bela hierarquia dos axiais" (Rancière, 1996, p. 20).

O sensível diz respeito ao estético e ao político simultaneamente, e a sua partilha é sempre de caráter polêmico, atingindo os modos de ser e as maneiras com que se distribuem as ocupações. Neste mundo há presenças que não adentram a seu campo de visibilidade, dizeres que não contam, perfazendo-se como um solo sempre controverso de relações sociais (Pallamin, 2010, p. 6).

Ao aproximar a política do conceito de experiência, a mudança social, para Rancière (1996, 2010), não significa um processo de conscientização de um determinado grupo ou classe social, já que esta não ocorre por meio de uma "tomada de consciência", tampouco, dirigida pela "classe social". Mas, sim, por meio de uma reconfiguração da experiência, do sensorium comum, por um processo estético. Não é realizado por um sujeito entendido como classe, mas pela "não-classe" (Rancière, 2009, 2011a), por dispositivos de subjetivação que inscrevem novas cenas, vozes, corpos, inteligibilidades e audibilidades, em um processo de desidentificação.

O autor aponta que o que irá ensejar a ação política poderá ser a luta de classes se essa luta criar uma ruptura com um determinado modelo hierárquico que produz um parte/sem-parte, visíveis/invisíveis, vozes/ruídos nos mais diversos campos que envolvem as relações de poder e dominação, que pode ser a classe, mas também outros regimes de subordinação em distintos contextos e períodos históricos como as relações de gênero, etnia, religião (...) ou qualquer outra forma hierárquica que revele um dano, um processo sensível de dominação e subalternização.

Um sujeito político não é um grupo que "toma consciência" de si, se dá voz, impõe seu peso na sociedade. É um operador que junta e separa as regiões, as identidades, as funções, as capacidades que existem na configuração da experiência dada, quer dizer, no nó entre as divisões da ordem policial e o que nelas já se inscreveu como igualdade, por frágeis e fugazes que sejam essas inscrições (Rancière, 1996, p. 52).

O sujeito político, entendido como um dispositivo de processos de subjetivação política, não une, mas desune a comunidade; não ocorre unicamente por um processo reflexivo e crítico, mas sim, estético. Não se dá de uma maneira geral, estrutural e estável, mas por "uma série de atos que não eram identificáveis no campo da experiência" (Rancière, 1996, p. 47), que emergem de forma precária e transitória, inscrevendo no simbólico "outros existentes, outros sujeitos do litígio político" (p. 47).

Assim, sob essa lógica, a perspectiva adotada por Rancière (2006) acerca da democracia cria distensões aos modelos clássicos utilizados para compreender a política, argumentando que estes escapam ao modo próprio da racionalidade política, ou seja, do dissenso. A crítica não recai exatamente no modelo liberal de democracia somente, Rancière (2006) aponta a insuficiência de discursos que tomam a democracia como forma de governo e não como política, em seus termos. O autor retoma os princípios filósoficos que a define: demos/katos: povo no poder. Ou seja, um ato democrático ocorre quando aquele que não tem competência ou título para governar passa a ser reconhecido como tendo direito à fala e à argumentação, portanto, quando um ato político desorganiza as formas sensíveis de estruturação do comum. A manifestação do sujeito político ocorre quando se desorganiza determinadas hierarquias, embaralhando as identidades, corpos e ocupações e produzindo novas gramáticas sensíveis e interpretativas de uma tal realidade.

\section{Métodos e Pprocedimentos}

O método deste estudo foi inspirado nas ideias de Bakhtin (2010) que compreende a sociedade como uma comunidade semiótica onde os signos, ideologicamente produzidos, vão refletir e refratar as práticas sociais. De acordo com este autor, os signos veiculam e produzem vozes, sentidos e representações que irão se (des)encontrar na sociedade, tornando esta uma arena de negociações, disputas e produções discursivas. Um signo, para este autor, se define por ser um instrumento semiotizado que produz mensagens, intertextualidades e interpretações. Assim, elegemos duas vias sígnicas para investigar as produções discursivas do Greenpeace: as entrevistas com pessoas envolvidas com esta ONG e as chamadas "ações diretas" que rompem os espaços públicos, determinados socialmente, e que são narradas através dos instrumentos de visibilidade da organização. 
Por constatarmos que o Greenpeace recorre tanto à produção de mensagens verbais (relatórios, notícias, posts, petições...) e não verbais (as ações diretas), optamos por coletar as informações deste estudo por meio da realização de entrevistas e do mapeamento virtual das ações diretas da organização.

Com o intuito de acessarmos o universo simbólico dos sujeitos envolvidos com o Greenpeace, buscamos investigar como ativistas, voluntários e funcionários vivenciam ou vivenciaram a experiência de estar e/ou pertencer ao Greenpeace. Para tanto, recorremos ao uso da entrevista semiestruturada (Gil, 1999), conduzida de forma aberta e dialogada (M. T. Freitas, 2003) com estas pessoas. A entrevista possuía um roteiro norteador para que os objetivos deste estudo fossem contemplados neste diálogo. Entretanto, as conversas foram manejadas de forma dialógica sendo que perguntas não previstas emergiam no próprio desenrolar das entrevistas. O roteiro foi composto por blocos temáticos e possuía como questão disparadora a seguinte pergunta: o que é o Greenpeace para você?

Entrevistamos um total de oito pessoas, sendo que dentre elas quatro eram profissionais do Greenpeace na época da entrevista, três eram ex-profissionais e um era ativista (voluntário). As entrevistas duraram de 1 a 2 horas, foram transcritas e submetidas à Análise de Conteúdo Temática a posteriori ${ }^{1} \mathrm{em}$ que, conforme Gil (1999), as categorias são elaboradas não apenas de acordo com os propósitos da pesquisa mas, também, pelos conteúdos manifestos emergidos durante o próprio processo das entrevistas.

Juntamente com a realização das entrevistas e com a finalidade de alcançarmos as produções discursivas não verbais do Greenpeace, optamos por analisar algumas das chamadas "ações diretas". As ações diretas se materializam em intervenções performáticas, inusitadas, dramáticas e irreverentes que, a nosso ver, são estratégias comunicativas não-verbais que buscam afetar e contagiar as pessoas por outras vias sígnicas distintas da palavra e da escrita. Entendemos que as performances realizadas pelo Greenpeace se configuram como signos que produzem determinados enunciados que irão entrar na arena de disputas discursivas no espaço coletivo.

A análise de conteúdo temática das entrevistas nos permitiu aproximarmos dos processos de significação e subjetivação de sujeitos que já haviam experienciado as ações diretas ${ }^{2}$, ao passo que a análise das imagens coletadas no site referentes às ações diretas nos possibilitou acessar o arranjo visual e estético destas intervenções, analisando-as a partir dos operadores teóricos da obra de Rancière e dos objetivos traçados nesta pesquisa. Dessa forma pudemos alcançar as formas (imagens) e conteúdos (falas) das ações diretas, compreendendo-as como cenas que inscrevem uma determinada gramática discursiva que vem interpelar a vida coletiva por meio do dissenso, do escândalo e do exagero no campo da luta ambiental.

Para acessarmos algumas das chamadas "ações diretas" do Greenpeace, optamos pelo rastreamento virtual no website da organização, já que, por limites temporais e geográficos, seria difícil conseguir analisar um número significativo de intervenções de maneira presencial. Recorremos ao website do Greenpeace/ Brasil no link "últimas atualizações" e ao website do Greenpeace/Espanha no link "últimas actualizaciones" nas postagens referentes ao período entre agosto de 2007 a janeiro de 2013, entre as quais selecionamos algumas ações que nos incitavam a pensar nas possíveis relações entre estética e política. $O$ critério de seleção destas ações foi o caráter de irreverência e criatividade que poderia enriquecer o debate sobre política e estética. Inicialmente, 36 ações foram selecionadas, por serem ações bastante performáticas, contudo, para compor este artigo, selecionamos apenas 3 intervenções como foco de nossas análises.

A pesquisa online tem crescido consideravelmente na última década e, dentre algumas vantagens do seu uso, está na maior agilidade e no maior alcance no processo de coleta de dados, permitindo ao pesquisador alcançar um patamar que, possivelmente, sem o recurso digital não o conseguiria. Além disso, o uso da ferramenta digital possibilita ao investigador acompanhar cotidianamente seu campo de pesquisa, o aproximando do dinamismo deste, permitindo-lhe acompanhar as mudanças e nuances de seu objeto de estudo. Por fim, pelo fato da linguagem da internet possuir diversas semioses (imagens, textos escritos, sons, vídeos, movimentos) fazendo emergir novas formas de discursos, possibilita uma multiplicidade de formas discursivas ao pesquisado e, por conseguinte, ao pesquisador (H. Freitas, Janissek-Muniz, Andriotti, Freitas, \& Costa, 2004; Mendes, 2009).

\section{Resultados e Discussão}

A chamada "ação direta" é um dos tipos das intervenções que o Greenpeace realiza, caracterizando-se 
por uma ação reivindicativa, pautada no princípio da "desobediência civil não violenta", que tem como propósito visibilizar, denunciar, pressionar, questionar, protestar algum acontecimento ou uma problemática relativos à temática ambiental.

Este tipo de militância emerge na década de 1970 com a chamada "arte ativista" que buscava, por meio de atos performáticos e de instalações artísticas, denunciar, protestar e provocar uma reação enérgica por parte da plateia (Fernández, 1999). Alguns movimentos políticos, como a Internacional dos Interacionistas e os Grafiteiros de Zurich surgem como formas de resistência a um modelo pragmático, rígido e racional de militância política. Estes movimentos, marcados pela mistura de arte, política e ironia, montam cenas "contra-informativas" de forma divertida, interpelando a ordem imperante discursiva, de forma a abrir novas possibilidades de interpretação por parte do espectador (Blisset \& Brunzels, 2006).

Justamente por escapar de um modelo mais tradicional de ação política, as ações diretas do Greenpeace interpelam modelos teóricos mais tradicionais que buscaram explicar as formas de mobilização e ação coletiva (Scherer-Warren, 2006), pois, não se trata de uma multidão, não se caracteriza por uma grande manifestação em praça pública, não emerge de forma espontânea e não possui um formato tradicional destas manifestações (pessoas carregando cartazes, faixas, carros de som).

Diferente do que estamos denominando de um modelo tradicional de ação política, as ações diretas do Greenpeace são cuidadosamente planejadas, conforme nos relata Paulo ${ }^{3}$, um dos ativistas "só vamos pra rua quando tudo tá muito bem planejado". A ação política conta, em geral, com um número pequeno de participantes e usa uma diversidade de elementos que a tornam um tanto quanto irreverente, tais como, fantasias, dramatizações, pinturas, grafite, escaladas, mergulho. Isso nos faz pensar acerca das possíveis formas de inovação na/da militância que, além de confundir as fronteiras do político/não político, nos convoca a pensar o que seria a própria militância na contemporaneidade (Maheirie et al., 2012; Mayorga, Castro, \& Prado, 2012; Menezes \& Castro, 2006; Oliveira, 2006; Prado \& Costa, 2009; Vinade \& Guareschi, 2007; Zanella, Levitan, Almeida, \& Furtado, 2012).

Para Oliveira (2006), o Greenpeace pode ser compreendido como um dos possíveis "corpos indisciplinados" na contemporaneidade. A autora afirma que as ações desta organização, tal como a arte performática, trabalham o corpo como um instrumento para configurar uma determinada experiência: "baseia-se na ação direta, no uso do corpo como ferramenta e na intensidade da experiência. Corpos suspensos em cordas, bloqueando passagens, corpos que confrontam grandes embarcações, corpos indisciplinados... que visa sacudir o espectador para levá-lo à reflexão" (p. 160).

O uso do corpo de forma "indisciplinada" surge na ação direta realizada contra a empresa OGX, uma das responsáveis pela exploração de petróleo na região de Abrolhos ("Deixe as baleias namorarem", 2011). Luana, militante do Greenpeace, conta que, antes de realizarem a ação direta, o Greenpeace tentou negociar (via telefone, e-mail e cartas) com a OGX, na tentativa de retirar esta empresa da atividade exploradora em Abrolhos. Como não obtiveram resposta da empresa, os ativistas, fantasiados de baleias e utilizando uma coleira no pescoço e uma máscara do Eike Batista, ocuparam o saguão do edifício e acorrentaram-se entre si, bloqueando a entrada do saguão, usando o corpo como ferramenta de "indisciplinação" do espaço ocupado (Figura 1). Além disso, jogaram um produto líquido e preto, insinuando ser óleo combustível, metaforizando a sujeira realizada no oceano pela base petrolífera, objetivada nos esguichos de "óleo" no saguão da empresa ("Enxotados pelo Eike", 2011), que era "tudo limpinho, branquinho..." (Luana).

A intensidade da experiência está no uso do corpo que toma parte de um espaço que não lhe pertence, um corpo que está onde não deveria estar, que diz o que não se deve dizer, configurando uma experiência poética de resistência. Partimos da ideia de que todo ato de resistência se configura em um corpo que, de forma indisciplinar, ocupa um lugar que não lhe pertence e se desloca de uma função ou identidade a qual foi "destinado", seja uma ação como essas do Greenpeace, seja em uma greve onde os corpos se negam a trabalhar. Talvez uma diferença entre estas formas de resistências políticas esteja nos impactos sensíveis causados nos espectadores que testemunham estas cenas dissensuais. Manchar de preto o que era "branquinho", como nos conta uma ativista, é uma maneira de perturbar o que antes estava organizado, sujar o que estava limpo, desestabilizar o que estava aprumado. Tornar visível o litígio, por meio do afetamento estético no cenário e nas pessoas testemunhas da ação, expressa uma potência peculiar deste tipo de intervenção realizada pelo Greenpeace. 


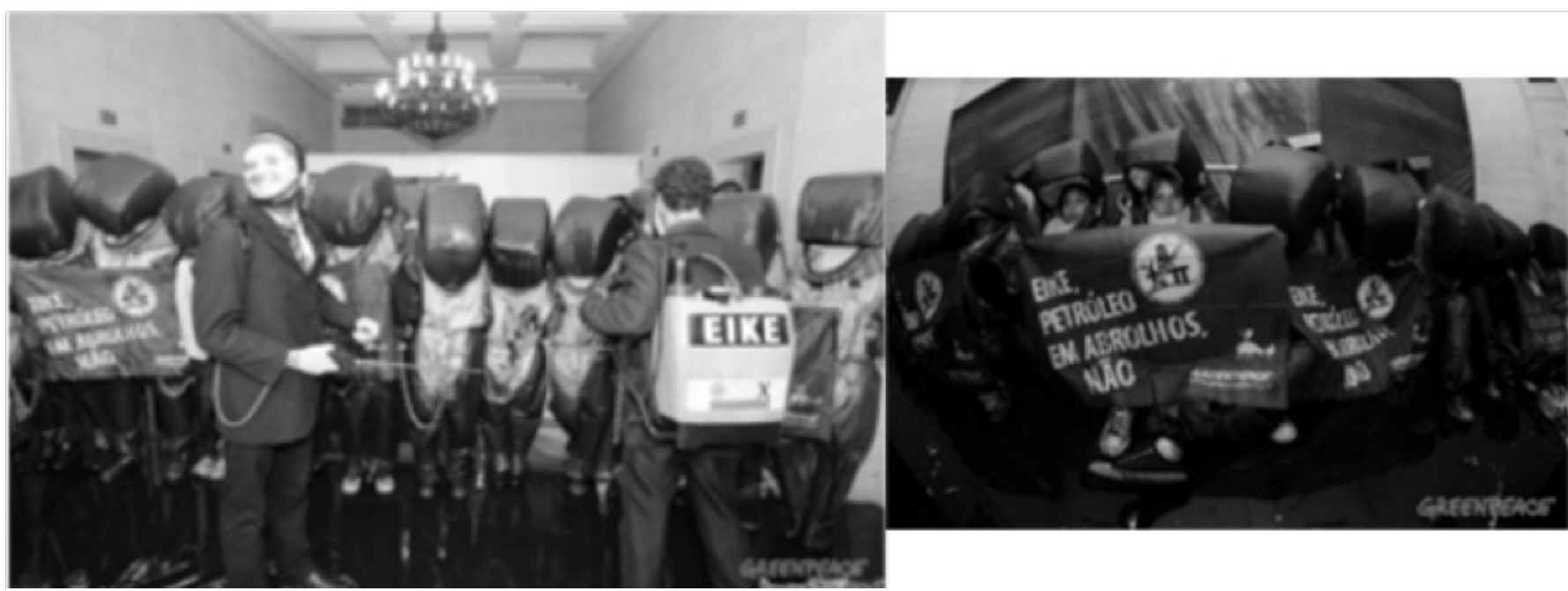

Figura 1. Ação Realizada na Empresa OGX, na Cidade do Rio de Janeiro (RJ), Brasil, em 2011.

Trazemos outra ação organizada pelo Greenpeace, que ocorreu no México em agosto de 2007, em uma praia turística chamada "Playa de los Muertos" em Puerto Vallarta. A ação política teve como reivindicação o controle da qualidade das águas das praias do México alertando para o aumento da poluição nestes locais turísticos com a chegada do período de férias. Para visibilizar esta questão, os ativistas inseriram na areia da praia um grande vaso sanitário inflável, com uma faixa contendo a mensagem "playas limpias ahora" ("Alcalde de Puerto Vallarta", 2007) (Figura 2).

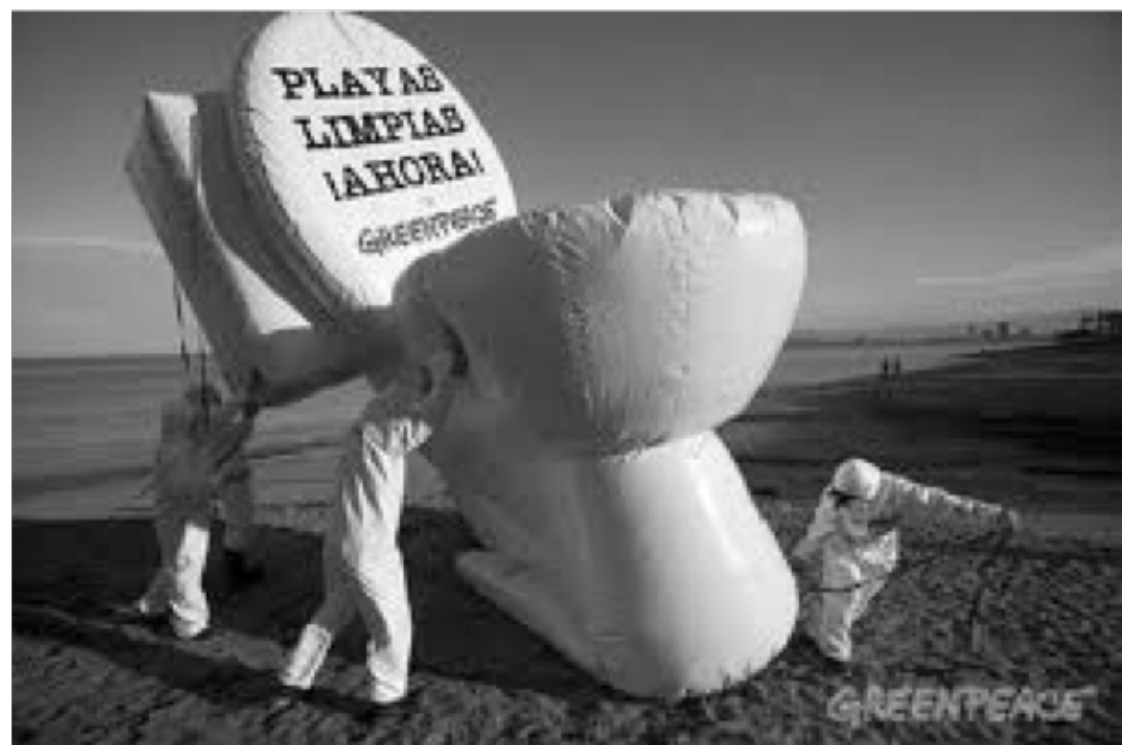

Figura 2. Ação Realizada na "Playa de los Muertos", Cidade, México, em 2007.

Por meio da inscrição de um novo objeto no universo simbólico, uma questão é encenada e visibilizada, buscando atrair o olhar do espectador. Metaforicamente, um objeto inusitado é inscrito de forma escandalosa e dramatúrgica, compondo uma mensagem dissensual, inscrevendo um novo agenciamento discursivo por meio de um ato estético, operando "un nuevo recorte del espacio material y simbólico" (Rancière, 2012a, p. 33). Assim, temos que para Rancière o processo de subjetivação política, calcado 
em agenciamentos discursivos e gramáticas interpretativas, provoca o que o autor denomina de "emancipação social" que se define por uma precária, fugaz e intermitente suspensão de determinadas hierarquias sustentadas por um específico regime de sensíveis. Nesse sentido, a mudança social pode ser pensada a partir de deslocamentos dos signos que produzem novas articulações discursivas que se materializarão na vida coletiva, já que sob esta lógica não é possível dicotomizar a esfera subjetiva, objetiva e política. O exagero, a dramaturgia e a demonstração argumentativa configuram-se como formas de intervenção no sensível que favorecem os processos de subjetivação política produzindo, como citado anteriormente, novos recortes materiais e simbólicos na partilha do sensível. Assim, entendemos que as ações diretas do Greenpeace são materializações de um determinado regime de sensibilidade (que apreende a sociedade a partir da lógica da sustentabilidade) que favorecem a emergência de subjetivações políticas que se objetivarão de maneira a provocar um dissenso com uma determinada forma hegemônica de partilha do sensível (capitalista, consumista e individualista).

Estas micro-situaciones, apenas distinguibles de las de la vida ordinaria y presentadas en un modo irónico y lúdico más que crítico y denunciador, tienden a crear o recrear lazos entre los individuos, a suscitar modos de confrontación y de participación nuevos. (Rancière, 2009, p. 5)

Ao inserir um grande vaso sanitário na praia, o Greenpeace possibilita a construção de uma leitura não habitual sobre este espaço, visando enfatizar aspectos que, em geral, não estão inteligíveis na vida ordinária. De acordo com Marzochi (2009), o Greenpeace utiliza cenas extraordinárias e incomuns para expressar uma mensagem que se compõe por um arranjo visual. Na pesquisa de Lycarião $(2008,2010)$, as ações diretas do Greenpeace são entendidas como "ações espetaculares" por, dentre outros motivos, utilizarem um forte apelo visual e dramático que buscam receber visibilidade e gerar notícia nos meios de comunicação de massa.

Este tipo de militância não parte de uma ideia de movimentos de massa, mas, sim, por meio da inscrição de cenas estéticas que politizam o espaço público de forma transitória, convidando a plateia a movimentos de reflexão e questionamento, podendo, desta maneira, abrir para novos sentidos na ordem vigente, catalisando processos de subjetivação política:
A política é assunto de sujeitos, ou melhor, de modos de subjetivação. Por subjetivação vamos entender a produção, por uma série de atos, de uma instância e de uma capacidade de enunciação que não eram identificáveis..., portanto caminha a par com a reconfiguração do campo da experiência. (Rancière, 1996, p. 47)

Partimos do entendimento de que o Greenpeace, bem como outros sujeitos coletivos dos movimentos ambientalistas, busca produzir outra forma de subjetivação no que tange à relação ser humano/natureza que não possui uma parte legitimada na ordem vigente (capitalista/ consumista). Possibilita o que Rancière (1996) denomina de "desentendimento": quando o mesmo objeto é significado e subjetivado de forma antagônica por sujeitos coletivos, caracterizando-se pelo desentendimento acerca de dois mundos que possuem duas formas paradoxais de inteligibilidade sobre a vida comum. O litígio configura-se no embate destas duas formas de apreender a realidade que irão disputar seu lugar e sua legitimidade na partilha do sensível, configurando a vida social como um incessante debate de gramáticas interpretativas.

A criação de uma cena escandalosa, dramática e exagerada busca provocar a forma de apreender o sensível, produzir giros estéticos, possibilitar novos agenciamentos de palavras e gramáticas interpretativas: imprimir à região de Abrolhos não apenas como um lugar paradisíaco, mas, também, um local que está sendo foco de exploração de petróleo. Com isso, colocam em litígio dois regimes discursivos (capitalista $X$ ambientalista), polemizando tal questão (os efeitos da exploração de petróleo na região de Abrolhos para o meio ambiente/sociedade).

De forma alguma entendemos que a inscrição de um novo sentido na comunidade faz com que a causa em questão seja resolvida, mas, a ordem vigente será, em alguma medida, interpelada e questionada, possibilitando a produção de um outro regime possível de visibilidades. Como nos relata uma ativista,

então você vai lá, se acorrenta na empresa do Eike Batista, você não tá parando a empresa dele, o petróleo continua sendo extraído em Abrolhos... Mas, este monte de baleias se debatendo no óleo chama atenção para um problema que é muito sério, mas de uma forma mais divertida...é uma estratégia para contagiar as pessoas...uma ação que mistura uma irreverência, uma sátira e tentando com isso atrair outras pessoas (Luana).

Esta fala nos aponta para uma importante reflexão sobre o que seria a mudança social na perspectiva de 
Rancière. A partir desta perspectiva, não há um modelo prescritivo, tão pouco permanente, para se alcançar uma sociedade igualitária, até porque sob esta lógica não é possível pensar em uma sociedade sem hierarquias, mas sim em espaços e momentos democráticos. Parece-nos que esta perspectiva aponta para um constante dinamismo e tensionamento de forças que ora vão romper, ora vão reforçar um determinado sistema de hierarquias. Nessa linha de raciocínio, os momentos democráticos emergiriam a partir de reconfigurações sensíveis que se materializarão de diversas formas na partilha do sensível.

Contudo, torna-se difícil, como o próprio autor aponta, determinar um momento preciso de estetização política na comunidade (Rancière, 2010b), isto é, localizar de forma objetiva e linear o efeito causado por uma determinada ação política, até porque não se trata de uma relação de causa e efeito, mas sim de processualidades que vão se articulando e provocando fissuras na lógica hegemônica vigente provocando mudanças sociais.

Assim, esta pesquisa não objetivou averiguar se e em que momento, cada uma destas ações do Greenpeace geraram, ou não, mudança social, até porque seria equivocado para esta perspectiva teórica analisá-las de modo isolado a um conjunto mais amplo de outras resistências políticas no campo ambiental. De forma geral, o que buscamos ressaltar é que estas ações produzem novos regimes de sensibilidades para apreender a sociedade que irão se materializar na partilha do sensível, compreendendo a política como um processo de subjetivação e objetivação.

A partir dessa compreensão, é inviável cindir o tripé social-político-subjetivo, tendo em vista que as formas de subjetivação são socialmente construídas, e que o político se configura como um produto de subjetivações que rompem com um determinado regime sensível hegemônico. Logo, podemos pensar que a mudança social é entendida como uma reconfiguração sensível das experiências que, por meio das subjetivações políticas, engendram novos agenciamentos discursivos que provocam desidentificações, rupturas e embaralhamento dos corpos, ocupações e competências.

Sendo assim, pensamos que as ações performáticas do Greenpeace possibilitam o ensejo de novas experiências sensoriais, revelando a animosidade que há entre a arte, o poético e a política. A arte e a política são linguagens estéticas que organizam o sensível, "são maneiras de dar a entender, de dar a ver, de construir a visibilidade e a inteligibilidade dos acontecimentos" (Rancière, 2010, p. 3).
Em uma ação realizada contra o posto Shell, devido à instauração de plataformas de exploração de petróleo no Polo Ártico (Figura 3), o Greenpeace ("Arte e protesto pelo Ártico", 2013) dá uma aesthesis à relação petróleo-urso polar, pois, quem se lembra da biodiversidade do Polo Ártico quando paramos em um posto de gasolina para abastecer o carro? Esta junção de evidências que não eram aparentemente articuladas é uma das características que Rancière (1996) entende como constituinte de um ato político, pois, por meio dele, alguns dados são articulados e produzem uma visibilidade que antes não era possibilitada.

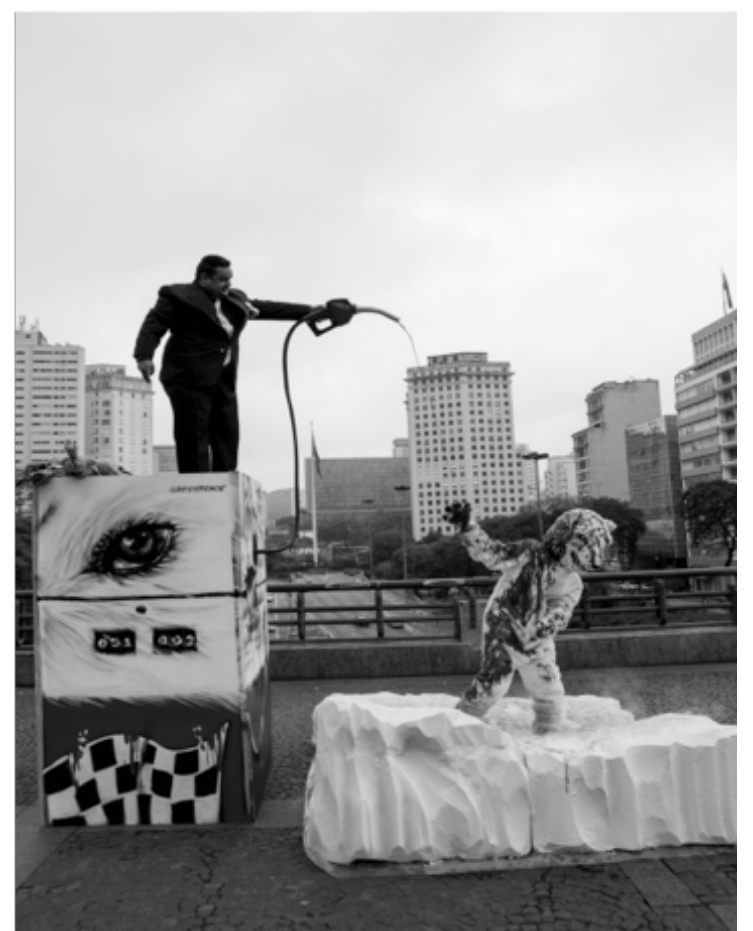

Figura 3. Ação Realizada no Viaduto do Chá, na Cidade de São Paulo (SP), Brasil, em 2013.

A intensidade da experiência performática realiza um ato de ficção que, para Rancière (2011b), é o ponto de início de uma ação política. A ficção não significa criar algo que está oposto à realidade, mas sim, esculpi-la a partir de outra posição sensorial, definido-a como "el vuelo de la imaginación que se inventa un mundo de ensueño" (p. 55), conferindo ao ato estético e político à imaginação, criação e sensação. Conforme Oliveira (2006), as performances são poéticas da ação "que visam a radicalização das emoções em uma espécie de ritual em que seus participantes são confrontados com seus próprios limites a fim de experienciar a vida de forma alargada" (p. 154). 
A política, além de ser um ato raro, pode ocorrer em lugares que tradicionalmente não atrelamos ao político, onde mais pensamos ser um ato político pode não ser político, e onde menos esperamos que haja algo de político, pode se configurar uma "revolução" cotidiana emancipatória. Assim, pensamos que as ações do Greenpeace são maneiras de construir e preparar as "revoluções" que, para Rancière (2009, 2010, 2011b), ocorrem no cotidiano da sociedade a partir da (re)configuração estética de partilhar o sensível, criando novas fronteiras entre o dentro-fora, contados/não contados, ruídos-vozes.

Nesse sentido, apostamos junto com Rancière (2010) que o substrato de uma transformação política se ancora na ruptura de modos tradicionais de perceber e sentir a realidade, ou seja, é necessário que possibilidades inéditas sejam vislumbradas pelas pessoas "para que sejam capazes de inscreverem novas maneiras de pensamento e ação no mundo em que vivem, transformando o universo de possíveis da percepção e da ação" (p. 12). Para o autor, os manifestantes colocam na rua um espetáculo que não tinha seu lugar, ocupam o espaço público para encenar uma nova redistribuição de papeis, encorpando personagens esquecidos na história e nas contas do Estado, provocando insurreições estéticas cotidianas.

O Greenpeace, assim, cria atos de insurreição, ainda que com poucas pessoas e em um formato aparentemente pouco político, mas, talvez, justamente por isso, é que a ONG se inscreve no simbólico de maneira política, pois, como afirma Rancière (2005b, p. 19), "é preciso não fazer política para fazer política". Estes atos, ao se apropriarem de forma irreverente e criativa do espaço público, fazem circular novos agenciamentos de palavras, gramáticas interpretativas, personagens esquecidos e histórias não contadas. Em um misto de performance, estética, ironia e exagero, instauram novas possibilidades de se encarnar e encenar o demos no cenário contemporâneo, contribuindo com as inscrições de espaços potencialmente políticos, irreverentes e criativos na esfera pública.

\section{Considerações finais}

Neste artigo analisamos algumas ações realizadas pelo Greenpeace sob o viés do debate teórico acerca da estética e da política. O Greenpeace, assim como outros sujeitos políticos contemporâneos, tem realizado uma militância de forma mais criativa e irreverente, nos convocando a pensar a militância sob o prisma da criatividade, imaginação e sensação.

No caso do Greenpeace, o uso da ironia tem servido como estratégia de criar atos de resistência chamativos e não-violentos, fazendo uso do exagero e do escândalo para introduzir enunciações que não eram identificáveis no campo da experiência coletiva. A performance, a dramatização e diferentes jogos argumentativos utilizados pelo Greenpeace, pautados em um forte apelo visual, auditivo e olfativo, buscam criar um novo "sistema de evidências sensíveis", rompendo com "modos habituais de perceber e sentir a realidade", de modo a "desarmar o monopólio da palavra legítima".

O Greenpeace tem se revelado como uma alternativa nas formas de inserção e transformação do espaço público em político, criando aberturas no campo dos possíveis das formas de contestação, reinventando e recriando formas de militância mais fluidas e leves na contemporaneidade que, em alguma medida, desestabilizam a gramática discursiva hegemônica da ordem vigente.

Nesse sentido, o Greenpeace revela-se como um sujeito político que opera como um dispositivo de subjetivação, redefinindo os territórios, o dentro-fora, as (in)competências e (in)visibilidades dos corpos e vozes que partilham o sensível. Por meio de atos de efeito surpresa, o Greenpeace revela a fragilidade da arkhé, inscrevendo novas comunidades de sentidos, novos agenciamentos de palavras e novas gramáticas interpretativas da vida comum.

Os diferentes sujeitos políticos contemporâneos vem nos revelando uma multiplicidade de jogos argumentativos que colocam em cena a confrontação de mundos alternativos, fazendo a política ser definida como uma "batalha incessante de gramáticas interpretativas" os quais criam "demonstrações estéticas dos direitos e manifestam o justo", esculpindo a realidade de uma forma mais igualitária e possibilitando experienciar a vida de forma mais alargada.

A polifonia e polimorfose das atuais práticas políticas surgem, então, como maneiras de dissensualizar o espaço público, visibilizando e reconfigurando um mundo paradoxal e litigioso onde seja possível vivermos, por meio do princípio da igualdade, a coexistência de mundos paradoxais. Pensamos que a hibridez das atuais formas de resistência presentes em nossa sociedade vem nos revelando a importância de criarmos cenas inéditas para que possamos reinventar 
a própria política, por meio da revolução estética do nosso cotidiano, inscrevendo espaços e momentos emancipatórios, de modo a fortalecer e intensificar os processos democráticos.

\section{Referências}

Alcalde de Puerto Vallarta nos ataca pero no limpia sus playas. (2007, 2 de agosto). Recuperado de http://www.greenpeace.org/mexico/ es/Noticias/2007/Julio/los-datos-hablan-por-s-mismos/

Arte e protesto pelo Ártico. (2013, 17 de agosto). Recuperado de http:// www.greenpeace.org/brasil/pt/Noticias/Arte-e-protesto-pelo-Artico/

Bakhtin, M. (2010). Marxismo e filosofia da linguagem: problemas fundamentais do método sociológico da linguagem. (14ª ed., M. Laud \& Y. F. Vieira, Trads.) São Paulo: Hucitec.

Blisset, L, \& Brunzels, S. (2006). Manual da guerrilla de la comunicación. Madrid: Virus.

Deixe as baleias namorarem. (2011, 2 de setembro). Recuperado de https://greenpeacerj.wordpress.com/tag/oceanos/

Enxotados pelo Eike. (2011, 31 de agosto). Recuperado de http://www. greenpeace.org/brasil/pt/Noticias/Nas-violentas-maos-do-petroleo/

Fernández, B. (1999). Nuevos lugares de intención: intervenciones artísticas en el espacio urbano como una de las salidas a los circuitos convencionales Estados Unidos 1965-1995 (Tese de Doutorado). Recuperado de http://eprints.ucm.es/tesis/19972000/H/1/ H1016501.pdf

Freitas, H., Janissek-Muniz, R., Andriotti, F. K., Freitas, P., \& Costa, R. S. (2004). Pesquisa via internet: características, processo e interface. Revista Eletrônica Gianti, 1-11. Recuperado de http://www.ufrgs.br/ gianti/files/artigos/2004/2004_140_rev_eGIANTI.pdf

Freitas, M. T. (2003). A perspectiva sócio-histórica: uma visão humana da construção do conhecimento. In S. Kramer; S. J. Souza, \& M. T. Freitas (Orgs.), Ciências Humanas e pesquisa. Leituras de Mikhail Bakhtin (pp. 26-38). São Paulo: Cortez.

Gabeira, F. (1988). Greenpeace: verde guerrilha da Paz. São Paulo: Clube do livro.

Gil, A. C. (1999). Métodos e técnicas de pesquisa social. São Paulo: Atlas.

Greenpeace. (2010). O surgimento do Greenpeace. Recuperado de http:// www.greenpeace.org/brasil/pt/quemsomos/Greenpeace-no-mundo/

Lycarião, D. (2008). O Greenpeace e os media: pode tanto espetáculo não degradar a esfera pública? Comunicação e Política, 26(3), 55-77.

Lycarião, D. (2010). Greenpeace, espetáculo e internet: o intercruzamento entre diferentes modos de comunicação para a sustentação de debates na esfera pública (Dissertação de Mestrado). Recuperado de http://hdl.handle.net/1843/FAFI-88QN2M

Maheirie, K., Hinkel, J., Groff, A. R., Muller, F. L., Gomes, M. A., \& Gomes, A. H. (2012). Coletivos e ralações estéticas: alguns apontamentos acerca da participação política. In C. Mayorga, L. R. Castro \& M. A. M. Prado (Orgs.), Juventude e a experiência da política no contemporâneo (pp. 143-167). Rio de Janeiro: Contra Capa.
Marzochi, S. F. (2009). Metamodernidade e política - A ONG Greenpeace (Tese de Doutorado). Recuperado de repositorio.unicamp.br/bitstream/REPOSIP/280859/1/Marzochi_SamiraFeldman_D.pdf

Mayorga, C., Castro, L. R., \& Prado, M. A. M. (2012). Juventude e os paradoxos da política. In C. Mayorga, L. R. Castro, \& M. A. M. Prado (Orgs.), Juventude e a experiência da política no contemporâneo (pp. 143-167). Rio de Janeiro: Contra Capa.

Mendes, C. M. (2009). A pesqusia on-line: potencialidades da pesquisa qualitativa da pesquisa virtual. Revista Digital Hipertextus, (2), 1-9. Recuperado de http://www.hipertextus.net/volume2/ConradoMoreira-MENDES.pdf

Menezes, J. A., \& Castro, L. R. (2006). Vicissitudes da subjetivação política juvenil na contemporaneidade. Psicologia Política, 6(11), 13-34. Recuperado de http://each.uspnet.usp.br/rpp/index.php/RPPEACH/ article/view/253/105

Oliveira, L. M. B. (2006). Corpos indisciplinados: ação cultural em tempos de biopolítica (Tese de Doutorado). Universidade de São Paulo, São Paulo.

Pallamin, V. (2010). Aspectos da relação entre o estético e o político em Jacques Rancière. Revista de Pesquisa em Arquitetura e Urbanismo, 12(2), 6-16. doi: 10.11606/issn.1984-4506.v0i12p6-16

Prado, M. A. M., \& Costa, F. A. (2009). A raridade da política e a democracia: os movimentos sociais entre sujeitos e identidades. In J. Bernardes \& B. Medrado (Orgs.), Psicologia social e políticas de existência: fronteiras e conflitos (pp. 71-83). Maceió: Abrapso.

Rancière, J. (1996). O desentendimento. São Paulo: Ed. 34.

Rancière, J. (2005a). A partilha do sensível: estética e política. São Paulo: Eixo.

Ranciére, J. (2005b). A política da arte e seus paradoxos contemporâneos. Recuperado de https://cidadaniaearte.wordpress.com/2013/11/17/a-politica-da-arte-e-seus-paradoxos-contemporaneos/

Rancière, J. (2006). O dissenso. In A. Novaes (Org.), A crise da razão (pp. 367-382). São Paulo: Companhia das Letras.

Rancière, J. (2009). Sobre políticas estéticas. (M. Arranz, Trad.). Barcelona: Museu d'Arte Contemporânea.

Rancière, J. (2010). El espectador emancipado. (D. A. Small, Trad.) Recuperado de http://www.questaodecritica.com. br/2008/05/o-espectador-emancipado/

Rancière, J. (2011a). Momentos políticos. Madri: Clave intelectual.

Rancière, J. (2011b). El tiempo de la igualdade: diálogos sobre política y estética. Barcelona: Herder.

Rancière, J. (2012). El mal estar en la estética. Madri: Clave intelectual.

Sakamoto, L. (2013). Mídia, rebeldia urbana e crise de representação. In E. Marciato et al. (Orgs.), Cidades rebeldes (pp. 95-100). São Paulo: Boitempo.

Scherer-Warren, I. (2006). Redes sociais na sociedade da informação. In R. Maia \& M. C. P. S. Castro (Orgs.), Mídia, esfera pública e identidades coletivas (pp. 215-227). Belo Horizonte: UGMG.

Vila, J. B. (2011). El tempo de la igualdade. In J. Rancière (Org.), El tempo de la igualdade (pp. 9-22). Barcelona: Herder Editorial.

Estudos de Psicologia, 23(2), abril a junho de 2018, 189-199 
Vinade, T. F., \& Guareschi, P. A. (2007). Possibilidades militantes na liquidez contemporânea. Revista Psicologia Política, 7(14), 1-20. Recuperado de http://pepsic.bvsalud.org/pdf/rpp/ v7n14/v7n14a04.pdf
Zanella, A. V., Levitan, D., Almeida, G. B., \& Furtado, J. R. (2012). Sobre ReXistências. Psicologia Política, 12(24), 247-262. Recuperado de http://pepsic.bvsalud.org/scielo.php?script=sci_arttext\&pi$d=S 1519-549 \times 2012000200005 \&$ lng $=$ pt\&tlng=pt.

\begin{abstract}
1. A análise de conteúdo temática gerou quatro categorias sendo que neste artigo estamos abordandoapenas uma delas, a saber, "As ações diretas: um enlace entre a estética e a política". As demais categorias foram: "Greenpeace: possibilidades, desafios e paradoxos"; "A mídia e o ativismo na rede virtual" e "As fronteiras entre a política e a polícia".

2. Os(as) entrevistados(as) haviam participado de algumas dessas ações diretas citadas neste artigo, seja como ativista (colaborador/a do Greenpeace) ou coordenador/a (profissional) destas intervenções. Por outro lado, algumas das ações descritas neste trabalho foram apenas abordadas por meio das imagens e descrições contidas no site da organização.
\end{abstract}

3. Todos os nomes utilizados neste trabalho são fictícios para garantir o anonimato dos sujeitos.

Marcela de Andrade Gomes, Doutora em Psicologia pela Universidade Federal de Santa Catarina (UFSC), é Professora Adjunta do Departamento de Psicologia na Universidade Federal de Santa Catarina (UFSC), Membro do Núcleo de Pesquisa em

Práticas Sociais, Estética e Política (NUPRA) e Coordenadora

da linha de pesquisa "Psicologia, Políticas Públicas e Direitos Humanos". Endereço para correspondência: Campos Universitário Reitor João David Ferreira Lima, s/n. Departamento de Psicologia, Bairro Trindade, Florianópolis, SC, CEP. 88040-900.

Telefone: (48) 37213510. E-mail: marcela.gomes@ufsc.br

Kátia Maheirie, Doutora em Psicologia Social pela Pontifícia Universidade Católica de São Paulo (USP), Pós-doutorado em Educação pela Universidade Estadual de Campinas (UNICAMP), é Pós-doutoranda em Psicologia Social pela Universitat Autònoma de Barcelona (UAB), Professora Titular do Departamento e do Programa de Pós Graduação em Psicologia na Universidade Federal de Santa

Catarina (PPGP/UFSC) e Membro do Núcleo de Pesquisa em Práticas Sociais, Estética e Política (NUPRA).E-mail: maheirie@gmail.com

Marco Aurélio Máximo Prado, Doutor em Psicologia Social pela Pontifícia Universidade Católica de São Paulo (PUC/SP), Pós-doutorado na Universidade de Massachusetts/Amherst Fulbright Fundation, é Professor Associado IV do Departamento e Programa de Pós Graduação em Psicologia da Universidade Federal de Minas Gerais (PPGP/UFMG) e Coordenador do Núcleo de Direitos Humanos e Cidadania LGBT. E-mail: mamprado@gmail.com

Lupicínio Iñiguez Rueda, Doutor em Filosofía e Letras (Psicología) pela Universitat Autònoma de Barcelona (UAB), é Professor de Psicologia Social no Departamento de Psicología Social da Universitat Autònoma de Barcelona (UAB). E-mail: lupicinio.iniguez@uab.cat

Recebido em 05.Jul.17 Revisado em 27.Mar.18 Aceito em 26.Jul.18 